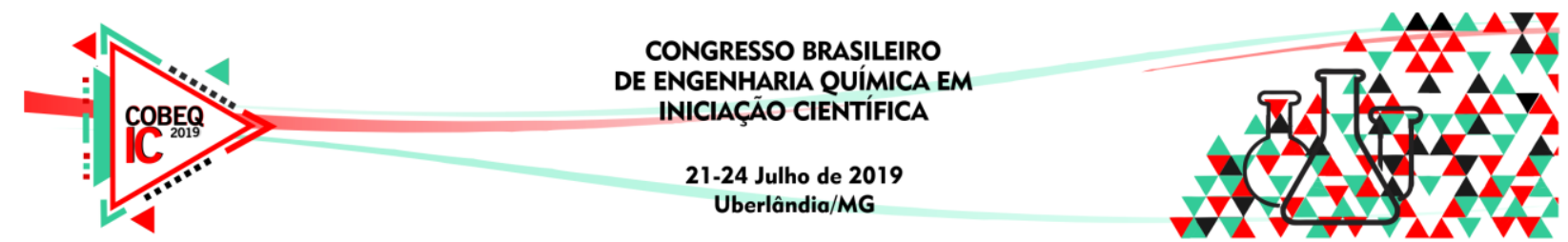

\title{
LEVANTAMENTO, ANÁlISE DE BOAS PRÁTICAS DE DESTINAÇÃO E TRATAMENTO DE RESÍDUOS SÓLIDOS NA REGIÃ̃ DE ARACRUZ - ES
}

\author{
B. L. PERONI ${ }^{1}$, U. S. CABRAL ${ }^{2}$ \\ ${ }^{1}$ Faculdades Integradas de Aracruz - FAACZ, Curso de Engenharia Química \\ ${ }^{2}$ Universidade Federal Fluminense, Departamento de Engenharia Química \\ E-mail para contato: barbaraleticiaperoni@gmail.com
}

RESUMO - Considerando a problemática ambiental causada pela geração de resíduos sólidos e o descarte inadequado dos mesmos, o presente trabalho visa apresentar um estudo de caso, sobre o tema, junto a uma empresa que faz a gestão do aterro sanitário de alguns municípios de pequeno e médio porte no estado do Espirito Santo. O estudo de caso é um método qualitativo que visa compreender o objeto em estudo e tem por objetivo explorar, descrever, explicar e/ou avaliar este objeto. Os processos citados são considerados importantes, já que visam minimizar a poluição do ambiente durante o descarte. $\mathrm{O}$ trabalho demonstra alternativas de tratamentos e destinação de resíduos sólidos que possam ser implantadas em um aterro sanitário de municípios no estado do Espirito Santo. Os resultados mostram que para a implantação depende de informações técnicas, como: relevo, condição climática, composição do efluente entre outros, assim os processos descritos tendem a ser uma base para a escolha e o desenvolvimento de possíveis tratamentos dos efluentes gerados por um aterro sanitário.

\section{INTRODUÇÃO}

Com o crescimento populacional, vem o aumento de consumo e consequentemente o aumento na geração de resíduos sólidos urbanos. A composição e a quantidade dos resíduos produzidos estão relacionadas diretamente, com o modo de vida, sua condição socioeconômica e a facilidade de acesso aos bens de consumo. De acordo com o panorama dos resíduos sólidos no Brasil 2016, feito pela Associação Brasileira das Empresas de Limpeza Pública (ABRELPE), o país gerou cerca de 214.405 toneladas por dia de resíduos sólidos urbanos (ABRELPE, 2016).

Esses resíduos eram destinados a lixões a céu aberto, que geram um mau cheiro, proliferam animais, ameaçam a saúde e a segurança pública, causam impactos ambientais que geralmente estão relacionados à contaminação do solo por chorume (ABRELPE, 2016).

Pensando nesta questão ambiental e visando o desenvolvimento sustentável foi criado pela Conferência das Nações Unidas sobre Meio ambiente e Desenvolvimento - Rio-92, um programa conhecido como Agenda 21. Esse documento, no que se refere a resíduos sólidos, informa que a degradação do meio ambiente é causada pelos padrões injustificáveis de produção e consumo, entre outros motivos, sendo necessário uma mudança significativa com a finalidade de reduzir a geração de resíduos (SILVA, 2017). 


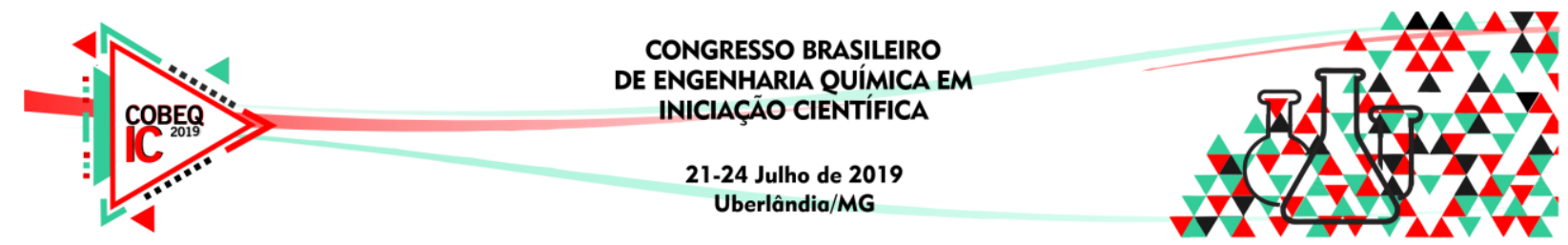

Partindo dos princípios estabelecidos pela agenda 21, foi criado a Lei n. ${ }^{\circ}$ 12.305/2010, que instituiu a Política Nacional de Resíduos Sólidos (PNRS), em que impõe a necessidade de acabar com a disposição final inadequada dos resíduos sólidos como medida de proteção ambiental, substituindo os lixões a céu aberto por aterros sanitários (BRASIL, 2010).

Dentre as metas estabelecidas pela PNRS, uma delas apontava que até agosto de 2014, todos os lixões a céu aberto deveriam estar extintos e todo o resíduo sólido gerado no país deveria ter seu destino final correto. Porém, segundo o levantamento feito pela ABRELPE no início de 2017, o Brasil possuía quase 3 mil lixões ou aterros irregulares em operação em 1.552 municípios que impactam a qualidade de vida de 77 milhões de brasileiros (ABRELPE, 2017).

O aterro sanitário consiste em um espaço destinado à deposição final de resíduos sólidos em camadas alternadas de lixo e terra para evitar mau cheiro e a proliferação de animais. Porém, resíduos sólidos depositados em celas de aterro sanitário estão sujeitos a processos de decomposição química e biológica, gerando efluentes líquidos e gasosos que também precisam ser tratados por serem extremamente poluentes ao ambiente (BAIRD, 2002).

O efluente líquido, denominado chorume, é escuro com odor desagradável e com elevado potencial poluidor formado pela umidade retida nos resíduos e água das chuvas que passam através das celas do aterro, carregando os produtos de degradação que possui elevada concentração de matéria orgânica e substâncias inorgânicas (SILVA, 2017).

O tratamento do chorume possui algumas dificuldades provenientes da alta concentração de matéria orgânica, nitrogênio, componentes tóxicos e alterações das características devido ao tempo que os resíduos permanecem em decomposição (MORAIS, 2005). Alguns processos como: aeração mecânica, adsorção em carvão ativado, osmose reversa, coagulação, floculação, sedimentação ou flotação, evaporação, oxidação química, fotoeletroquímico, lagoas anaeróbias e lagoas facultativas, recirculação são aplicados no tratamento do chorume (BELTRÃO, 2006).

Já o efluente gasoso é o biogás, combustível de alto valor energético, obtido por processo de fermentação da matéria orgânica, pela ação das bactérias anaeróbias que compõem os compostos orgânicos presente nos resíduos sólidos. Ele é composto por metano, dióxido de carbono, traços de vapor de água, gás sulfídrico, nitrogênio, oxigênio, hidrogênio, monóxido de carbono, amônia, mercaptanas e outros gases (CAMPOS, PRADO, 2008).

Esse gás é agressivo, em termos de corrosão, causando impactos ambientais relativos ao efeito estufa e impactos sociais devido ao seu odor. Por causa do levado poder calorífico e queima fácil, o gás é capturado, conduzido para combustão em queimadores e podem ser usados para geração de energia elétrica ou aquecimento de caldeiras (CABRAL, 2009).

Sendo assim, o presente trabalho tem como objetivo investigar, segundo técnicas de tratamento do chorume e do biogás proveniente de aterro sanitário no município de Cariacica, a possibilidade de implantação de processos similares no município de Aracruz.

\section{DESENVOLVIMENTO}




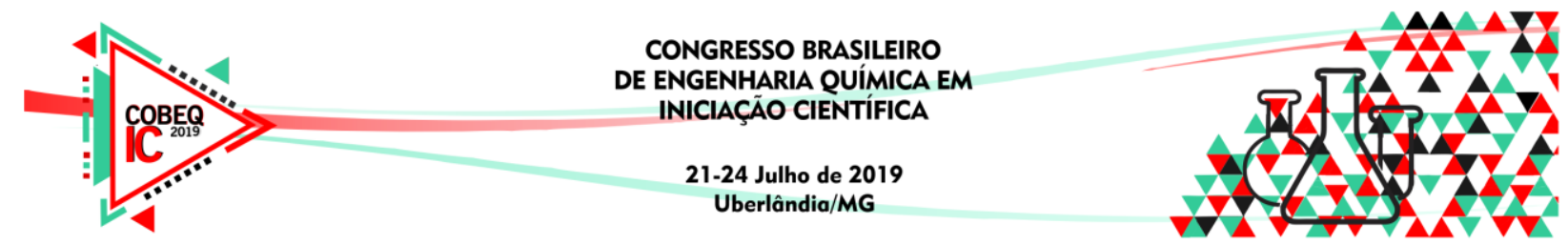

A metodologia desse trabalho foi divida em 4 etapas: a primeira consiste em um estudo bibliográfico de processos físicos, físico-químicos e biológicos para o tratamento de efluentes líquidos, principalmente o chorume e efluente gasoso, na forma de biogás em aterros sanitários para municípios de pequeno porte. A segunda em um estudo de campo com servidores de Secretaria Municipal de Transporte e Serviços Urbanos de Aracruz, no setor responsável pela coleta de resíduos sólidos.

A terceira corresponde a uma pesquisa junto à empresa que faz a gestão do aterro sanitário no município de Cariacica (Marca Ambiental) através de questionário enviado por email, com o objetivo de analisar as formas de tratamento dos efluentes utilizados no município. E por fim, realizar uma comparação entre as diferentes técnicas para tratamento do chorume com o que é realizado no município de Cariacica.

\section{RESULTADOS E DISCUSSÕES}

No Estado do Espírito Santo existem apenas 5 aterros sanitários, onde estão localizados nos municípios de Aracruz, Cachoeiro de Itapemirim, Cariacica, Colatina e Vila Velha.

Cariacica é um município localizado na Região Metropolitana da grande Vitória. Por sua localização privilegiada é considerada o grande elo entre o litoral e a região serrana do estado. Segundo o jornal "A Gazeta", de 21 de novembro de 2017, foram coletadas 284 toneladas por dia de lixo úmido, média de 88 mil toneladas por ano. O custo para coletar, transportar e aterrar o lixo comum e os resíduos infectantes foram de mais de $\mathrm{R} \$ 20$ milhões por ano. Já de lixo seco era 50 toneladas por mês, $0,67 \%$ de tudo que foi coletado na cidade.

Seu aterro sanitário está localizado a $16 \mathrm{~km}$ do centro da cidade, sendo de encargo da empresa privada Marca Ambiental e recebe em média 1400 toneladas de RSU por dia. Sendo o primeiro aterro sanitário privado do estado, preparado para receber resíduos domiciliares, comerciais, portuários, inertes, de serviços de saúde e resíduos industriais.

São 14 municípios que destinam seus resíduos para o aterro da Marca Ambiental, entre eles estão: Vitória, Serra, Cariacica, Viana, Domingos Martins, Marechal Floriano, Santa Leopoldina, Fundão, Alto Rio Novo, Itarana, Mantenópolis, Santa Maria de Jetibá, Santa Teresa e Laranja da Terra.

Os resíduos, classificados como Classe II A, dos 14 municípios que são destinados ao aterro da Marca Ambiental, não sofrem nenhum tipo de separação, visto à grande quantidade de resíduos recebido diariamente, predominante a essa quantidade recebida está a contaminação dos resíduos recicláveis quando dispostos misturados. A separação deve ser feita na fonte geradora, uma vez que ao serem coletados misturados, os resíduos recicláveis contaminados não possuem mais valor para a reciclagem.

Para o gerenciamento dos resíduos não perigosos da Classe II A, a Marca Ambiental, possui unidades de disposição final constituídas por células impermeabilizadas com camadas de argila compactada, impermeabilização com mantas de polietileno de alta densidade (PEAD), rede de drenagem e tratamento de líquidos percolados, sistema de tratamento do biogás e, ao final, processo de recomposição de taludes e revegetação das células. A Estação de Tratamento de Efluentes possui a capacidade para tratar $10,0 \mathrm{~m}^{3} / \mathrm{h}$ de efluente bruto. 


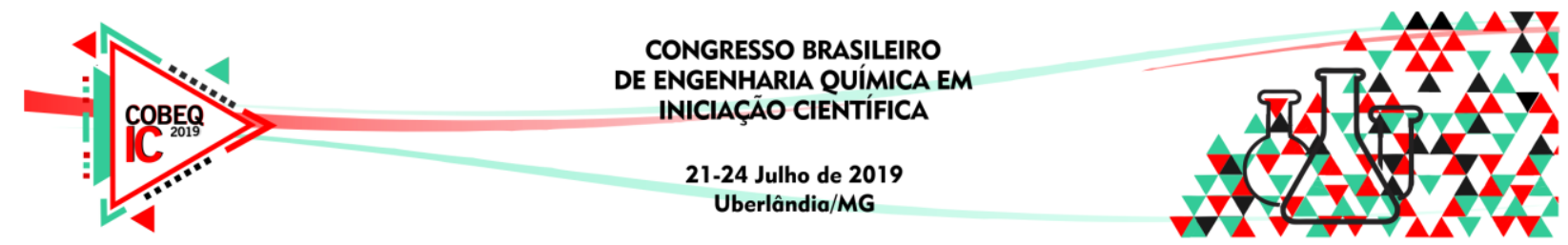

Aracruz é um município localizado no litoral norte do estado do Espírito Santo e em 2017 eram coletados em média 58,08 toneladas por dia de resíduo sólido urbano. Seu aterro sanitário fica localizado a cerca de $7 \mathrm{~km}$ do centro da cidade no bairro Areal e sendo de encargo de uma empresa privada. Em 2014, o aterro sanitário recebeu em média 350 toneladas por dia de lixo produzido em 13 cidades. Entre elas estão: Águia Branca, Água Doce do Norte, Aracruz, Ecoporanga, Ibiraçu, Itarana, Jaguaré, João Neiva, Linhares, Montanha, São Gabriel da Palha, Sooretama e Vila Valério.

Ainda de acordo com o jornal "A Gazeta", o volume aterrado nos aterros da empresa privada de Aracruz é, em média 303,7 toneladas por dia de resíduos e no aterro da Marca Ambiental, Cariacica, cerca de 1.216,3 toneladas por dia.

\subsection{Chorume}

Os processos para tratar o chorume foram determinados através de estudos, realizado nos laboratórios da Marca Ambiental. Onde os processos selecionados apresentaram resultados de elevada eficiência para a remoção da matéria orgânica, como DBO e DQO, cor e outros materiais tóxicos como nitrogênio amoniacal. $\mathrm{O}$ sistema de tratamento utilizado é dividido em etapas, conforme apresentado na Figura 1.

Figura 1 - Etapas do sistema de tratamento adotados pela empresa Marca Ambiental.

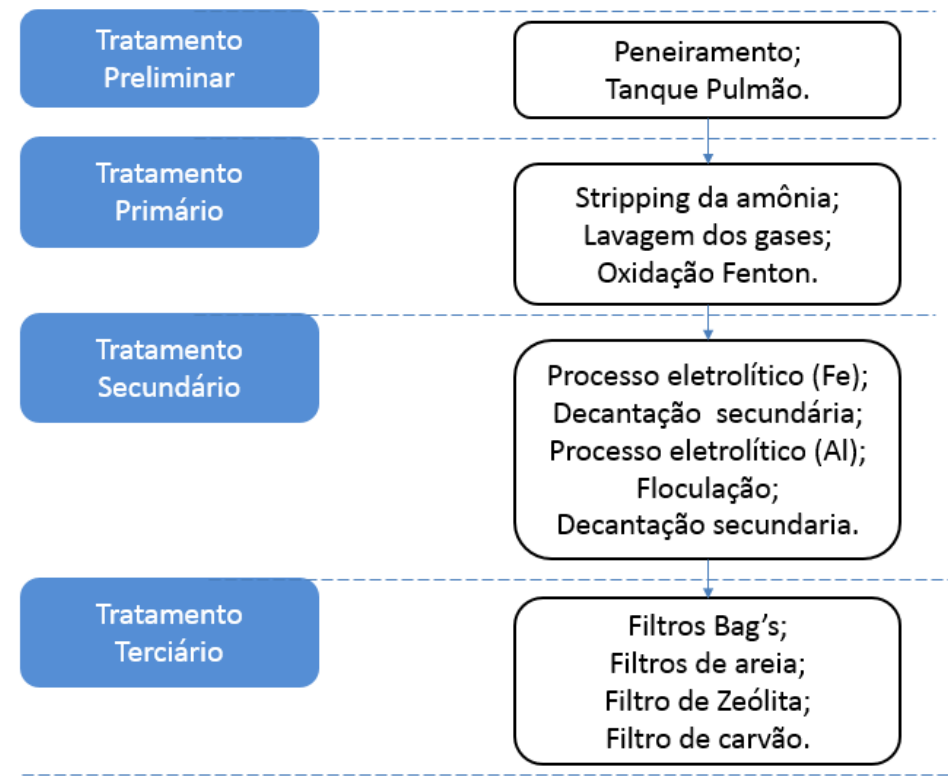

O chorume gerado no aterro é drenado e conduzido para a lagoa de equalização, onde os picos de vazão e carga serão absorvidos e o material homogeneizado. Então o chorume é bombeado para a ETE, onde primeiro, passa por um peneiramento e, em seguida é levado para um tanque trocador de calor, nele o chorume é aquecido com influência de uma caldeira. Após passar pelo trocador de calor, o efluente, por conter elevados níveis de amônia, é submetido ao processo de stripping (aeração mecânica) para a redução desses elevados níveis de amônia, sendo a forma mais eficiente para a remoção de amônia concentrada no chorume, tornando a concentração de $\mathrm{NH}_{3}$ inferior a 1000 ppm. 


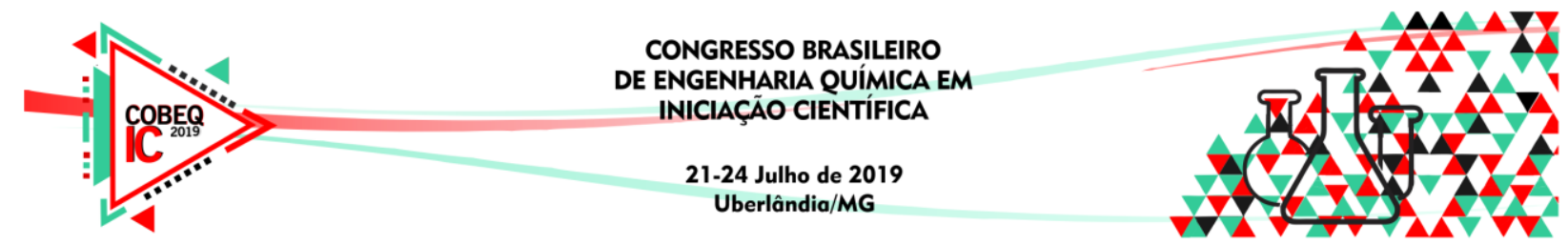

Com a concentração de amônia baixa, o efluente é bombeado para o tanque de préoxidação. A pré-oxidação ocorre em meio ácido $(\mathrm{pH} 5,0)$ e com adição de peróxido de hidrogênio, usando um catalisador, esse processo é denominado de oxidação fenton. Onde é possível observar uma redução em média 35 a 50\% da matéria orgânica.

Assim o efluente apresenta as características ideais para o próximo processo, ele segue para o processo eletrolítico, que é a aplicação de corrente elétrica contínua e frequência variável na solução de chorume. Esse processo acontecerá em duas etapas eletrolíticas, ferro e alumínio. O sistema consiste na combinação de três processos que ocorrem simultaneamente dentro da célula eletrolítica: a eletrocoagulação, a eletrofloculação e a eletroflotação.

Uma grande vantagem de utilizar o processo de eletrocoagulação, é fato de gerar o agente coagulante "in situ", eliminando a necessidade de um coagulante químico, que acontece na coagulação convencional. Na primeira etapa eletrolítica, utiliza os eletrodos de ferro para promover a eletrocoagulação, no qual se tem a liberação de ferro para o meio, para coagular o efluente. Em seguida, o chorume segue por gravidade para o decantador, que retém todo o material dissociado na etapa anterior liberando um efluente clarificado.

Esse efluente clarificado é levado para a segunda etapa eletrolítica, onde se utilizam os eletrodos de alumínio para a eletrocoagulação igual na primeira etapa, porém, nesta, há a liberação de alumínio para o meio, exercendo novamente a função de coagular o efluente. $\mathrm{O}$ efluente já coagulado vai para a etapa de floculação, em que há adição do floculante. Após ocorre uma segunda decantação secundária para reter todo o material floculado, assim o chorume saí clarificado dessa etapa e vai para o tratamento terciário.

O tratamento terciário começa com um processo de filtração em filtros bags de três diferentes de diâmetros, $150 \mu, 100 \mu$ e $50 \mu$, para garantir que o efluente fique sem sólidos suspensos. Em seguida, o efluente irá para filtro com leito de areia, onde serão removidos os materiais finos indesejáveis. Após, é feita a filtração em leito de zeólita, onde será absorvido o restante de amônia presente no efluente. Por último, o efluente passa pela filtração em leito de carvão ativado para reter todo o restante da matéria orgânica presente e do odor, garantindo que o mesmo esteja de acordo à legislação vigente.

\subsection{Biogás}

O gás formado pela decomposição dos resíduos dispostos no aterro é capturado e levado a tanques chamados flares, onde é feito a oxidação térmica reduzindo o metano, convertendoo em gás carbônico, água e traços de demais produtos de combustão. A energia liberada proveniente da oxidação térmica, ainda não possui uma finalidade, mas a utilização desse potencial energético do biogás está em fase de estudo com previsão para operar em 2019.

\section{CONCIDERAÇÕES FINAIS}

A empresa privada que faz a gestão do aterro sanitário de Aracruz não possui um programa que auxilia no desenvolvimento de trabalhos acadêmicos que tenha a temática voltada para a gestão de resíduos e ainda possui normas que não disponibiliza algumas informações sobre o aterro sanitário e os processos utilizados, o que dificultou a obtenção de informações para comparação e adquirir melhores resultados. 


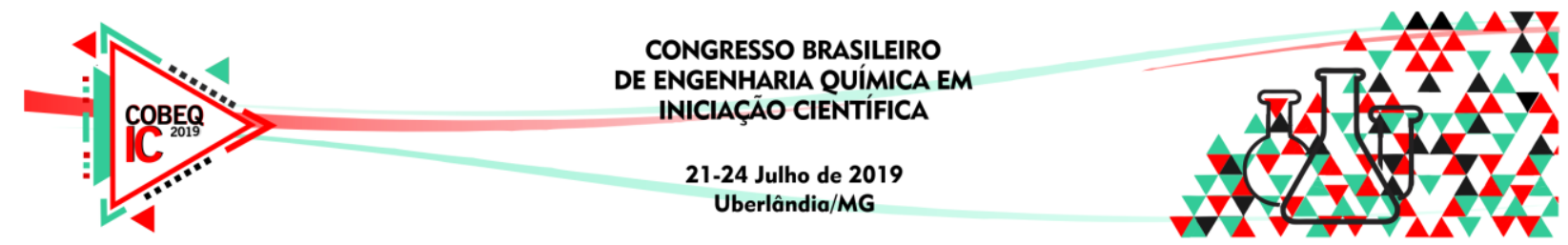

Em consideração as análises dos processos na literatura e, na prática, presume-se que haja condições satisfatórias para a capacidade de implantação e desenvolvimento de técnicas que apresentam uma alta eficiência no tratamento de efluentes líquidos e gasosos gerados pelo aterro, para se enquadrar nos parâmetros exigidos pela legislação ambiental vigente sendo possível a reutilização do efluente tratado para outras atividades da empresa ou seu descarte.

Porém, para afirmar tal capacidade de implantação deve-se considerar parâmetros técnicos, como: relevo, condição climática, composição do efluente entre outros parâmetros. Essas informações não foram disponibilizadas pela empresa responsável pelo aterro sanitário de Aracruz, portanto, sugere-se que esses estudos sejam objeto de trabalhos futuros.

\section{REFERÊNCIAS}

ABRELPE. Panorama de Resíduos Sólidos no Brasil. Associação Brasileira de Empreses de Limpeza Pública e Resíduos Especiais, São Paulo, 2013. 111 p.

ABRELPE. Panorama de Resíduos Sólidos no Brasil. Associação Brasileira de Empreses de Limpeza Pública e Resíduos Especiais, São Paulo, 2016. 59 p.

ABRELPE. Panorama de Resíduos Sólidos no Brasil. Associação Brasileira de Empreses de Limpeza Pública e Resíduos Especiais, São Paulo, 2017.

BAIRD, C. Química ambiental, 2ª edição. Porto Alegre: Editora Bookmsn, 2002.

BELTRÃO, K. G. Q. de B. Sistema de Barreira Bioquímica como Alternativa para o Tratamento de Percolado. Tese de Doutorado. Universidade Federal de Pernambuco, 2006.

BRASIL. Presidência da República. Lei $\mathrm{n}^{\circ}$ 12.305, de 02 de agosto de 2010. Lei de Política Nacional de Resíduos Sólidos; altera a Lei 9.605 de 12 de fevereiro de 1998; e dá outras providências, Brasília, 02 de agosto de 2010.

CABRAL, R. C. Aproveitamento do Biogás em Aterros Sanitários: Especificações Construtivas Beneficiando Aspectos Ambientais e Energéticos. 2009. 129 p.

CAMPOS, C. M. M.; PRADO, M. A. C. Produção de Biogás no Tratamento dos Efluentes Líquidos do Processamento de Coffea Arabica L. Em Reator Anaeróbico Uasb para o Potencial Aproveitamento na Secagem do Café. Revista A Ciências e Agrotecnologia, Lavras, V. 32, n. 3, p. 938-947, maio/jun., 2008.

MORAIS, J. L. Estudo da Potencialidade de Processos Oxidativos Avançados, Isolados e Integrados com Processos Biológicos Tradicionais, para Tratamento de Chorume de Aterro Sanitário. Curitiba, 2005.

SILVA, C. Z. Codigestão Anaeróbia de Lixiviado de Aterro Sanitário e Glicerol. Programa de Pós-Graduação. Universidade Estadual do Oeste do Paraná. Cascavel - Paraná, 2017. 